\title{
A ETAPA ESCOLAR DA CONFERÊNCIA INFANTOJUVENIL DE MEIO AMBIENTE: ANÁLISE DOS PROJETOS DE EDUCAÇÃO AMBIENTAL
}

Erika Regina de Oliveira Minetto ${ }^{1}$ Antônio Augusto Rossotto loris ${ }^{2}$ Daniela Maimoni de Figueiredo ${ }^{3}$

Resumo: Este trabalho objetivou avaliar as Conferências Nacionais Infantojuvenis pelo Meio Ambiente, quanto a participação dos Estados e, particularmente, quanto aos projetos elaborados pelas escolas de Mato Grosso. A análise dos projetos foi quali-quantitativa, incluindo avaliação da estrutura, do conteúdo, da execução e do atendimento aos objetivos, tanto das CNIJMA quanto da Política Nacional de Educação Ambiental (EA). Mato Grosso apresentou baixo desempenho, com menor participação relativa das escolas da região onde se situa a capital em relação a outras duas regiões. Verificou-se que a proposta da Conferência foi, de maneira geral, adequada, mas sua compreensão e implementação foi incipiente no cotidiano escolar e no atendimento aos objetivos da EA. A maioria dos executores dos projetos não possui uma concepção crítica da EA e tem dificuldade em integrar os conteúdos de forma interdisciplinar e no seu contexto socioambiental, sendo um potencial obstáculo à formação de cidadãos participativos.

Palavras-chave: Políticas Públicas; Interdisciplinaridade; Bacia Hidrográfica.

\footnotetext{
1 Universidade Federal de Mato Grosso, Programa de Pós-Graduação em Recursos Hídricos. E-mail: erikarom.rh@gmail.com

${ }^{2}$ Cardiff University. E-mail: iorisa@cardiff.ac.uk

3 Universidade Federal de Mato Grosso, Programa de Pós-Graduação em Rec. Hídricos, Bolsista CapesPNPD. E-mail: dani_figueiredo@uol.com.br
} 


\section{Introdução}

A Educação Ambiental (EA) é definida, pela sua Política Nacional (PNEA - Lei no 9.795, de 27/04/1999), como "processos por meio dos quais o indivíduo e a coletividade constroem valores sociais, conhecimentos, habilidades, atitudes e competências voltadas para a conservação do meio ambiente, bem de uso comum do povo, essencial à sadia qualidade de vida e sua sustentabilidade" (BRASIL, 1999, p. 01). Nas escolas, entende-se a EA como o processo percorrido pelo educando em busca de conhecimento sobre questões ambientais, com a finalidade de desenvolver uma nova percepção a respeito do conceito de meio ambiente, bem como se tornar também um agente transformador da conservação e da preservação dos recursos naturais (FERREIRA et al., 2019). As Diretrizes Curriculares Nacionais para a EA nas escolas mencionam que essa deve considerar "a interface entre a natureza, a sociocultura, a produção, o trabalho, o consumo, superando a visão despolitizada, acrítica, ingênua e naturalista ainda muito presente na prática pedagógica das instituições de ensino" (BRASIL, 2013, p. 523). Para tanto, a EA deve ser crítica e emancipatória, exigindo que os conhecimentos sejam apropriados, construídos, de forma dinâmica, coletiva, cooperativa, contínua, interdisciplinar, democrática e participativa, voltados para a construção de sociedades sustentáveis (TOZONI-REIS, 2006).

$O$ processo de EA, tanto individual quanto coletivo, deve, portanto, considerar as relações socioambientais e suas causas e efeitos. As causas, de maneira geral, referem-se à forma como ocorre esta relação sob a influência de ideologias ocidentais e pressões da economia capitalista, geralmente pautada na noção de apropriação, de não-pertencimento e de que os recursos naturais são inesgotáveis, ou seja, devem sustentar um crescimento contínuo e infinito. Como consequências, tem-se constatado nos ecossistemas, nos biomas e na biosfera intensas alterações físicas, químicas, biológicas e sociais, sendo que as sociais implicam, geralmente, em aumento da desigualdade e deterioração da qualidade de vida humana. Este quadro, que caracteriza as sociedades contemporâneas influenciadas pela globalização dos mercados e processos socioeconômicos insustentáveis, revela que o impacto dos humanos sobre o meio ambiente tem tido consequências cada vez mais complexas e deletérias, sendo assim, a Educação Ambiental assume cada vez mais uma função transformadora, na qual a co-responsabilização dos indivíduos torna-se um objetivo essencial para promover o desenvolvimento sustentável (JACOBI, 2003, p.193).

Neste sentido, diversas práticas e entendimentos de como a EA poderia contribuir na reversão deste quadro foram desenvolvidas. Dourado, Belizário e Paulino (2015) mencionam que a EA mais conservadora procura mitigar os efeitos do capitalismo e acredita na sua capacidade de se reinventar, sendo focada no uso racional dos recursos, incluindo a ideia de desenvolvimento sustentável. Já a EA mais radical busca a superação do capitalismo como modo de vida, o qual está centrado na exploração dos recursos naturais e na produção de desigualdades. Dentro destas duas grandes correntes, vários

revista brasileira educação ambiental 
autores propuseram inúmeras classificações e tendências político-pedagógicas na EA. Por exemplo, Layrargues e Lima (2014) afirmam que, mesmo assumindo o risco de elaborar um quadro parcial e incompleto, existem três macrotendências para a EA: 1- Conservacionista; 2- Pragmática e 3- Crítica.

As correntes citadas e suas subdivisões apresentam um imenso desafio frente à necessidade de promoção da EA nas escolas, que pode ser enfrentado, em parte, com projetos que permitam a percepção das diferentes relações socioambientais de maneira participativa, para que ações concretas e transformadoras possam ser pensadas e executadas. Neste sentido, a partir de 2002 (ano de regulamentação da PNEA) o Ministério da Educação (MEC) e o Ministério do Meio Ambiente (MMA) passaram a trabalhar juntos, formando o Órgão Gestor da PNEA (CRUZ; MAIA, 2015, p. 9), tendo como um dos primeiros eventos públicos a I Conferência Nacional Infantojuvenil de Meio Ambiente (CNIJMA, em 2003 em Brasília). Neste, participaram diversas instituições públicas das duas áreas, bem como organizações da sociedade civil, que resultou na elaboração, de forma participativa, da Carta dos Jovens Cuidando do Brasil e, posteriormente, em 2004, no Programa Vamos Cuidar do Brasil com as escolas: sistema de Educação Ambiental no ensino formal, visando fortalecer a EA nas escolas dos estados e municípios. Este Programa adota uma metodologia que transforma a escola em um espaço de debate político e de construção de conhecimento coletivo, em que a opinião dos jovens é respeitada e valorizada. Isso é possível através da Comissão de Meio Ambiente e Qualidade de Vida (Com-Vida) que é "uma forma de organização na escola que se baseia na participação de estudantes, professores, funcionários, diretores e comunidade" (BRASIL, 2012a, p. 08). Esta deve ser uma comissão permanente, que tem entre suas atribuições, a missão de elaborar o projeto de ação colocando-o em prática após o evento.

A Com-Vida parte de uma concepção freireana a respeito dos Círculos de Aprendizagem e Cultura, um movimento que teve início por Paulo Freire na década de 1960 e que incentivou organizações populares a se articularem rumo à transformação das realidades sociais opressoras (MARINHO, 2009, p. 16).

A proposta do programa Vamos Cuidar do Brasil com as Escolas reforça o que podemos chamar da sexta competência do professor, que é a sua iniciativa e atuação política para desenvolver projetos sobre problemas socioambientais e, para isso, se engajar em instâncias de discussões de EA e articular parcerias (CRUZ; MAIA, 2015, p. 9).

Considerando que para participar deste Programa, as escolas devem apresentar um projeto de EA, o presente trabalho objetivou avaliar estes projetos, especificamente os que foram desenvolvidos pelas escolas de Mato Grosso para a IV CNIJMA, usando-os como indicadores do alcance dos objetivos e da adoção dos princípios propostos pela PNEA neste Estado, tendo em vista que esta conferência "consistiu em uma ação estratégica para a implementação desta política" (BRASIL, 2017). 
Visando discutir o papel e a contribuição do Estado de Mato Grosso no âmbito das Conferências, serão apresentados aqui também os resultados de sua participação com relação aos demais Estados brasileiros e com relação às regiões de planejamento de seu território. Embora o foco deste trabalho seja Mato Grosso, a realidade então verificada com esta pesquisa pode servir como reflexão a outros Estados do país que também participaram das CNIJMAs.

Vale destacar que Mato Grosso é um Estado particularmente estratégico do ponto de vista ambiental, pois além de apresentar em seu vasto território três grandes biomas brasileiros, Floresta Amazônica, Pantanal e Cerrado, possui em sua área as principais nascentes de três grandes regiões hidrográficas, Amazônica, Paraguai e Tocantins-Araguaia, implicando em responsabilidade e necessidade de participação social na gestão e no cuidado destes recursos naturais, com vistas ao uso sustentável para as atuais e futuras gerações. Os contextos histórico, econômico, social e ambiental, especialmente por ser um Estado fundado em uma economia vinculada ao setor primário, onde prospera o agronegócio com escasso planejamento social e de uso dos recursos naturais, muitas vezes é conflitante com as características naturais de Mato Grosso e evidencia a dificuldade e a grande necessidade em inserir a EA, especialmente nas escolas. A EA nas escolas tem um papel muito importante porque desperta em cada aluno a busca de soluções para os problemas ambientais que ocorrem, principalmente, em seu cotidiano e no desenvolvimento da consciência de é imprescindível utilizar com inteligência os recursos naturais (FERREIRA et al., 2019).

\section{Histórico das Conferências}

A CNIJMA é a ação mais ampla de EA, desenvolvida nas escolas no âmbito nacional. Entre as metas propostas estão a construção das Agendas 21 escolares, contribuir com iniciativas da Organização das Nações Unidas (ONU), como a Década da Educação para o Desenvolvimento Sustentável e Metas do Milênio, criar e fortalecer as Com-Vidas, além de movimentos como os Coletivos Jovens de Meio Ambiente (CJs) e a Rede da Juventude pelo Meio Ambiente e Sustentabilidade (REJUMA) em parceria com as Secretarias Estaduais e Municipais de Educação. Todas as interfaces que compõe as CNIJMAs são complexas e envolvem vários Programas, cuja análise detalhada seria bastante extensa e, portanto, não foram aprofundadas neste trabalho.

As Conferências acontecem em três etapas, sendo a primeira nas escolas e comunidades, fazendo parte da etapa mais rica do processo, quando são elaborados e desenvolvidos os projetos, que foram analisados no presente trabalho; a segunda de forma descentralizada nos municípios e estados e a última, etapa nacional (culminância), de forma centralizada (BRASIL, 2006), cujo histórico e características das quatro realizadas até 2013 estão sintetizados na Tabela 1. Observa-se nesta figura uma tendência de redução no número de pessoas mobilizadas e de municípios da primeira para as duas Conferências seguintes, com tendência de aumento na quarta edição. Nessa

revista brasileira educação ambiental 
edição, constata-se semelhanças com a anterior quanto ao tema e material orientativo adotado para o desenvolvimento dos projetos nas escolas, apesar do maior intervalo de anos entre ambas. Vale mencionar que somente os projetos da quarta Conferência encontram-se disponíveis no site do evento, razão pela qual foram objeto de estudo do presente trabalho.

Tabela 1: Histórico e síntese das características de cada Conferência Nacional Infantojuvenil pelo Meio Ambiente, de 2003 a 2013.

\begin{tabular}{|c|c|c|c|c|}
\hline & I CNIJMA & II CNIJMA & III CNIJMA & IV CNIJMA \\
\hline Ano / Período de realização & $2003^{(1)}$ & $2005 / 2006^{(2)}$ & $2007 / 2008 / 2009^{(3)}$ & $2012 / 2013$ \\
\hline $\begin{array}{c}\mathrm{N}^{\circ} \text { de Municípios } \\
\text { participantes }\end{array}$ & $3.461^{(3)}$ & $2.865^{(2)}$ & $2.828^{(3)}$ & $3.000^{(5)}$ \\
\hline $\mathrm{N}^{\circ}$ de Escolas participantes & $15.452^{(3)}$ & $11.475^{(2)}$ & $11.631^{(3)}$ & $16.945^{(4)}$ \\
\hline $\begin{array}{c}\mathrm{N}^{\circ} \text { de delegados na etapa } \\
\text { Nacional }\end{array}$ & $378^{(1)}$ & Mais de $500^{(2)}$ & $642^{(3)}$ & $673^{(5)}$ \\
\hline Faixa etária dos delegados & De 11 a 15 anos & De 11 a 14 anos & De 11 a 14 anos & De 11 a 14 anos \\
\hline $\mathrm{N}^{\mathrm{o}}$ de pessoas mobilizadas & $5.658 .877^{(3)}$ & $3.801 .055^{(2)}$ & $3.723 .442^{(3)}$ & 9 milhões $^{(5)}$ \\
\hline $\begin{array}{c}\text { Duração (desde o lançamento } \\
\text { até a culminância no evento } \\
\text { nacional) }\end{array}$ & 6 meses & 10 meses & 1 ano e 11 meses & 1 ano e 5 meses \\
\hline $\begin{array}{l}\text { Temas/Subtemas (com o } \\
\text { percentual de escolas que } \\
\text { trabalhou cada tema) }\end{array}$ & $\begin{array}{l}\text { Como vamos cuidar } 1 \text { - de nossa } \\
\text { água }(41 \%), 2 \text { - dos seres vivos } \\
(11 \%), 3 \text { - dos nossos alimentos } \\
(9 \%), 4 \text { - da nossa escola }(18 \%) \text { e } \\
5 \text { - da nossa comunidade }(16 \%)- \\
\text { Outros }(5 \%)^{(1)}\end{array}$ & $\begin{array}{c}\text { Mudanças climáticas }(26 \%), \\
\text { biodiversidade }(32 \%), \\
\text { segurança alimentar e } \\
\text { nutricional }(24 \%) \text { e } \\
\text { diversidade étnico-racial } \\
(18 \%)^{(2)} .\end{array}$ & $\begin{array}{c}\text { Água }(45 \%), \text { Terra } \\
(34 \%), \text { Fogo }(10 \%) \\
\text { e } \operatorname{Ar}(11 \%)^{(3)}\end{array}$ & $\begin{array}{c}\text { Água, Terra, Fogo e Ar } \\
\text { Dados ainda não } \\
\text { divulgados. } \\
\text { Mesmo material } \\
\text { orientativo da III } \\
\text { CNIJMA }\end{array}$ \\
\hline
\end{tabular}

Fontes: (1) Brasil, 2003; (2) Brasil, 2006; (3) Brasil, 2009; (4) Coordenação Geral De Educação Ambiental, 2013; (5) Portal Brasil, 2013.

\section{Material e Métodos}

Esta pesquisa foi realizada em duas etapas, detalhadas em seguida: i) participação de Mato Grosso e dos demais Estados, com levantamento comparativo da participação de todos os Estados brasileiros na IV CNIJMA e das regiões de planejamento de Mato Grosso (MT); ii) análise dos projetos do Estado de Mato Grosso, sendo estes desenvolvidos pelas escolas deste Estado para participação na IV CNIJMA.

Quanto a forma de abordagem desta pesquisa, conforme Marconi e Lakatos (2012), as duas etapas incluem pesquisas quantitativas objetivas e descritivas, porém, na segunda etapa, foi adotada também a análise dos projetos, buscando aprofundar em questões subjetivas de forma exploratória. A pesquisa exploratória objetiva proporcionar maior familiaridade com o problema para torná-lo mais explícito ou constituir hipóteses; pode-se dizer que o objetivo principal destas pesquisas é o aprimoramento de ideias ou a descoberta de intuições (LIMA et al., 2012, p. 130). 


\section{Participação de Mato Grosso e dos demais Estados}

As análises comparativas entre os diferentes Estados do país e entre as diferentes regiões de planejamento de Mato Grosso que participaram da IV CNIJMA foram realizadas com base no Censo Escolar 2010 (MEC/INEP), considerando apenas as séries finais do Ensino Fundamental $\left(5^{\underline{a}-} 8^{\underline{a}}\right.$ série ou 6-9a ano), que são as que participam do Programa. Esses dados foram obtidos através de solicitação junto ao Serviço de Informação ao Cidadão (e-SIC/MEC). $\mathrm{Na}$ análise descritiva e comparativa, adotou-se no presente estudo o número total de projetos disponíveis para consulta (14.937), que deveriam ser anexados no momento da inscrição de cada escola, porém, o número total de inscrições de escolas de todo o país (16.945) diferiu da quantidade de projetos disponíveis. Estes dados foram compilados e tabulados para a análise comparativa.

Para Mato Grosso, também utilizou-se o número de projetos inscritos por escola em cada município, sendo que estes foram agrupados nas 12 regiões de planejamento adotada pela administração pública do Estado. A quantidade de projetos apresentados por todas as escolas públicas e privadas mato-grossenses (123) também diferiu da quantidade total de escolas inscritas (148), como ocorreu em nível nacional.

\section{Análise dos projetos do Estado de Mato Grosso}

A $4^{a}$ edição da CNIJMA propôs a elaboração de um projeto com o tema "Vamos Cuidar do Brasil com Escolas Sustentáveis", onde cada escola participante deveria escolher um dos quatro subtemas sugeridos: água, terra, fogo e ar. Com isso, foram analisados em detalhes os 123 projetos das escolas de Mato Grosso, que foram elaborados na primeira etapa desta Conferência. Todos estes projetos foram obtidos no site da Conferência em abril de 2014 (MINISTÉRIO DA EDUCAÇÃO, 2014).

A fim de respaldar o trabalho das escolas, MEC e MMA organizaram uma "Cartilha passo a passo", que orienta na elaboração dos projetos, apontando que a escolha do projeto e do tema deve estar dentro de critérios como: importância e urgência para a escola, facilidade de implementação e disponibilidade de recursos, sejam eles humanos, financeiros ou tecnológicos. Menciona ainda que os professores poderiam ajudar a melhorar a compreensão, como criar e manter a Com-Vida, entre outras reflexões. Um projeto deve ter como objetivo a reflexão sobre o desejo de transformar a realidade, tendo em mente a resolução de uma situação-problema local (BRASIL, 2012a).

Como critério de avaliação dos projetos na presente pesquisa, primeiramente foram verificadas as características das escolas participantes e a estrutura padrão dos projetos, quais sejam: 1) identificação dos executores: tipo de administração (municipal, estadual ou privada) e perfil das escolas (urbana ou rural); 2) temas escolhidos: água, terra, fogo e ar; 3) apresentação 
do Marco Zero (diagnóstico): "é o momento em que a escola se encontra antes de iniciar as ações planejadas para depois poder comparar se houve transformações" (BRASIL, 2012a); 4) Estrutura padrão do projeto, conforme a cartilha de orientação: Justificativa ou Introdução, Objetivos, Metodologia, Resultados esperados, Avaliação, Cronograma, Recursos financeiros, Referências bibliográfica (não foi considerado a capa, apenas a parte escrita), incluindo a apresentação de fotos; 5) trabalhos de Educomunicação: maneira de unir educação com comunicação que defende o direito que as pessoas têm de produzir e difundir informação e comunicação no espaço educativo (BRASIL, 2012a).; 6) desenvolvimento de Ecotécnicas: conjunto de intervenções tecnológicas no ambiente que se baseia na compreensão dos processos naturais e tem como foco a resolução de problemas com o menor custo energético possível e com uso eficiente de bens naturais (BRASIL, 2012b).

Parte destes dados, especialmente a identificação dos executores, que não estava disponível nos projetos, foram obtidos por meio de documentos cedidos pela SEDUC-Secretaria Estadual de Educação (planilha com dados das escolas e projetos selecionados) e ainda junto ao Q-Edu, um sistema online de consulta sobre dados da educação brasileira (QEDU, 2015).

$\mathrm{Na}$ análise qualitativa do conteúdo dos projetos desenvolvidos pelas escolas de Mato Grosso, foram avaliados: 7) clareza dos projetos; 8 ) se houve participação da comunidade escolar (estudantes, professores, funcionários e comunidade); 9) se a interdisciplinaridade foi mencionada e/ou adotada como prática nas atividades propostas.

Neste sentido, a metodologia adotada buscou analisar todos os aspectos

e conteúdos, objetivos apresentados nos projetos das escolas, além de analisar as questões subjetivas, especificamente as mencionadas nos itens 7 a 9 acima, mesmo considerando suas limitações metodológicas. Com isso, os dados possíveis de serem mensuráveis numericamente foram analisados conjuntamente com a abordagem qualitativa, que mesmo sendo em parte subjetiva, contou com a experiência do pesquisador, conforme observado por Frigotto (2010), procurando inferir sobre a realidade escolar com base no texto dos projetos avaliados embasado nas teorias educacionais aplicáveis.

\section{Resultados}

\section{Participação de Mato Grosso e dos demais Estados}

Para todo o país, a pesquisa da quantidade de projetos inscritos, que neste estudo foram considerados como a mesma quantidade de escolas participantes da IV CNIJMA, apresentou uma participação média de $26,3 \%$ em relação ao total de escolas públicas e privadas brasileiras. A Figura 1 mostra a porcentagem de escolas que participaram da IV CNIJMA, em relação ao número total de escolas em cada Estado. 


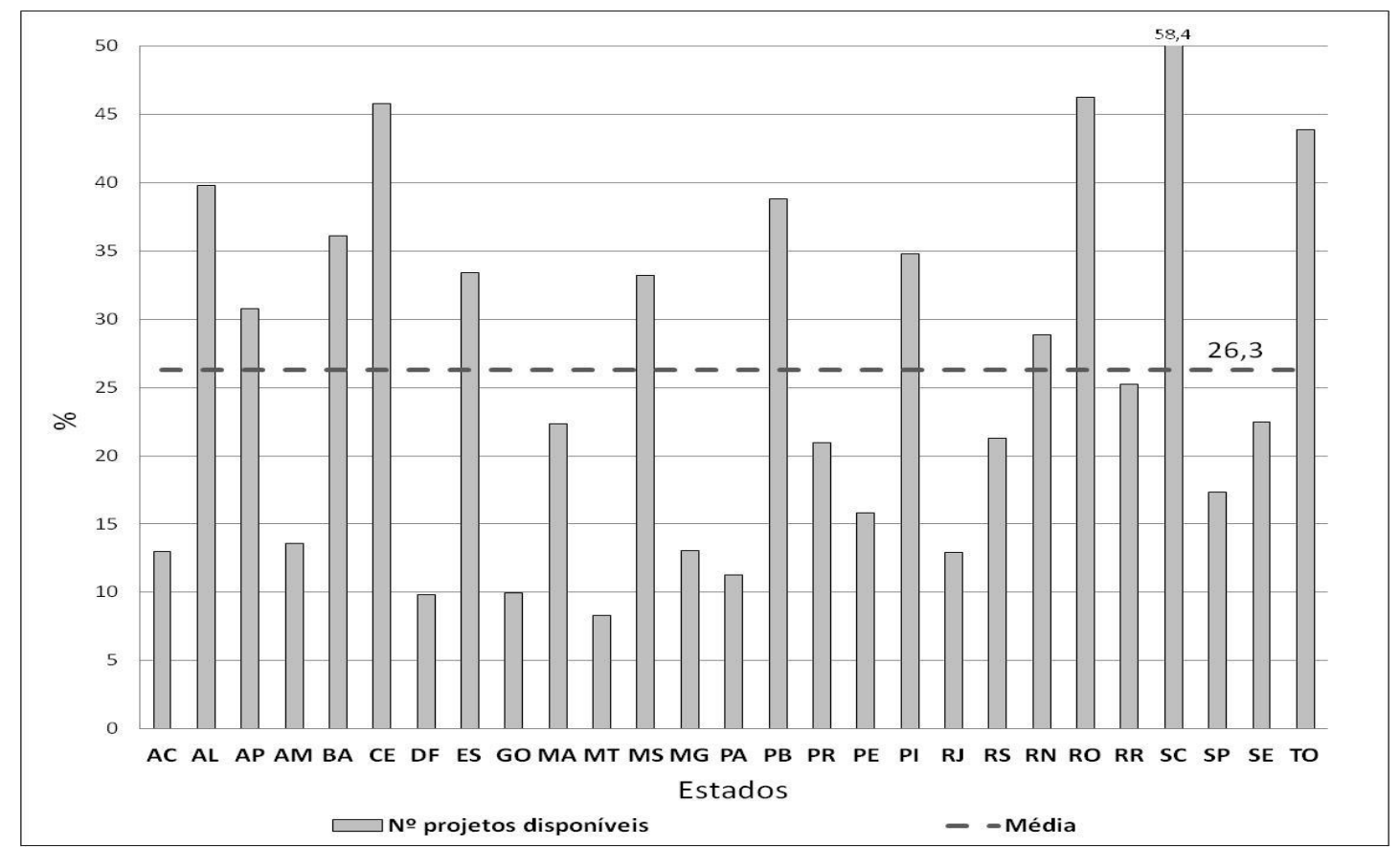

Figura 1: Percentual de escolas participantes da IV CNIJMA em relação ao total de escolas em cada Estado.

Fonte: Elaborado pelos autores a partir de dados do MEC/INEP Censo Escolar, 2010

O Estado de Mato Grosso (8,3\%) e o Distrito Federal (9,8\%) tiveram percentual de projetos inscritos abaixo de 10\%, meta do Programa. Ceará, Rondônia e Santa Catarina superaram os $45 \%$.

A análise por região de planejamento de Mato Grosso mostra que a Região $\mathrm{VI}$, que tem como polo a cidade de Cuiabá, capital do Estado, foi a que concentrou a maior porcentagem de escolas do Estado (22,9\%) e a maior quantidade de projetos apresentados (33 no total, sendo 13 do tema água), por ser a região com maior concentração populacional e, por conseguinte, de escolas. Contudo, ao se analisar o percentual de projetos em relação ao número total de escolas, nota-se que a Região X, que tem a cidade de Sorriso como polo, foi a que apresentou o melhor desempenho em relação ao envolvimento das escolas, com 30,9\%, seguida da Região III, com $21,3 \%$ (Figura 2). Mas duas ressalvas devem ser feitas a esse respeito: dos sete municípios que compõem a Região X, apenas dois participaram: Lucas do Rio Verde, com $16,4 \%$ de escolas participantes (município com maior participação no Estado), e Sorriso, com $14,5 \%$ de escolas participantes (segundo município com maior participação no Estado). O município de Confresa, da Região III, foi o terceiro com maior participação no Estado ( $12 \%$ de suas escolas).

Dos 141 municípios do Estado, 38 tiveram escolas que inscreveram projetos, correspondendo a $27 \%$ dos municípios. A região de planejamento $\mathrm{VI}$ (Cuiabá) teve maiores porcentagens de municípios participantes, com 61,5\%, seguido da Região XI (Juara), com $50 \%$ e da Região II (Alta Floresta) com $40 \%$. 


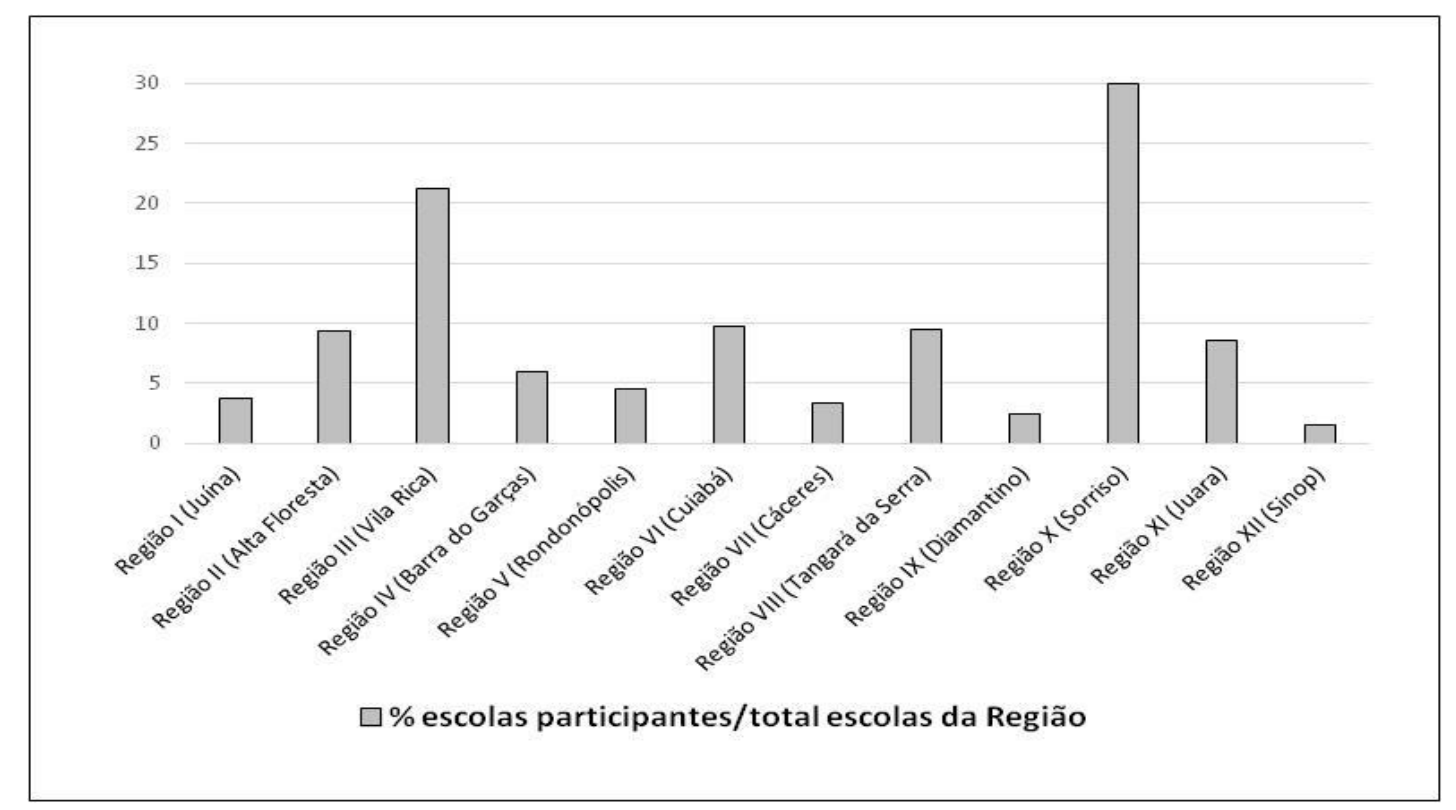

Figura 2: Percentual de escolas de Mato Grosso que apresentaram projetos na IV CNIJMA em relação ao número total de escolas por Região de Planejamento do Estado, com as respectivas cidades polo. Fonte: Elaborado pelos autores

Considerando todas as escolas do Estado, a Região VI (Cuiabá) foi a que apresentou maior quantidade de projetos, com $2,2 \%$ das escolas de MT, seguido da Região X (Sorriso), com 1,2\% das escolas e Região III (Vila Rica) com $1,1 \%$ das escolas.

\section{Análise dos projetos do Estado de Mato Grosso}

$\mathrm{Na}$ análise integral dos 123 projetos inscritos pelas escolas de Mato Grosso para o IV CNIJMA, observou-se que, entre as escolas participantes, a maior parte pertence a rede municipal de ensino (68\%), seguida da rede estadual $(29,5 \%)$ e privada $(2,5 \%)$. Deste total, $60,6 \%$ dos projetos foram selecionados para a etapa estadual.

$\mathrm{Na}$ identificação do perfil das escolas, observou-se que $63,1 \%$ pertence à zona urbana e $36,9 \%$ a zona rural, sendo $22,2 \%$ de assentamentos, $6,7 \%$ de comunidades indígenas e 4,4\% de quilombolas, grupos que fazem parte das escolas de ações afirmativas (BRASIL, 2009).

Sobre o tema escolhido, os projetos priorizaram terra, com $58 \%$, seguido de água com $36 \%$, fogo com $4 \%$ e ar com $2 \%$. Não foi possível identificar o tema escolhido em $36,7 \%$ dos projetos, sendo que destes, alguns optaram em trabalhar os quatro, tendo ainda alguns que escolheram um subtema para cada bimestre. Em geral, para estes casos, notou-se uma superficialidade nas propostas elencadas. Algumas escolas se inscreveram no subtema terra, mas explicaram que poderiam "pertencer" ao subtema água ou ar. Isso mostra que 
os responsáveis pela elaboração da parte escrita do projeto traziam uma visão mais ampla e interdisciplinar das questões ambientais. Das escolas que escolheram o tema água, 19,4\% citaram atividades envolvendo rios, córregos, nascentes e matas ciliares, as demais consideraram a água apenas dentro do ambiente escolar.

O "Marco Zero", um tipo de diagnóstico, onde a escola deveria "observar, contar, medir, pesar, descrever como é o ambiente da escola por duas semanas" (BRASIL, 2012b, p. 46), visando a criação de projetos voltados à realidade observada, foi um dos aspectos também sugeridos na cartilha de orientação. Embora nenhuma escola tenha utilizado em seu projeto o termo "Marco Zero", em aproximadamente $20 \%$ dos projetos foi possível identificar alguma forma de diagnóstico do problema identificado, embora de maneira superficial.

$\mathrm{Na}$ estrutura do projeto, mesmo considerando que a "Cartilha Passo a Passo" (BRASIL, 2012a) tenha orientado que este deveria conter de duas a quatro laudas, não foi estabelecido nenhum padrão sobre o tipo e o tamanho da fonte, espaçamento ou margens e ainda como proceder com gráficos e tabelas. Embora a maior parte dos projetos $(77,9 \%)$ contemplasse o número de laudas estipulada, ou seja, entre duas e quatro laudas, encontrou-se uma variedade muito grande na formatação deles. A formatação de um trabalho pode ser considerada uma tarefa simples de ser executada e deveria estar detalhada de maneira clara e normatizada nas orientações contidas na cartilha, a fim de evitar a elaboração de projetos pouco documentados e pouco claros quanto às atividades propostas. Seria importante que os tópicos fossem inseridos separadamente (Introdução, Objetivos, Metodologia, Cronograma, Marco Zero etc.), no momento da inscrição (on line) para padronização dos projetos que, ao final do processo pudessem ser visualizados de forma integral e sistematizada. Isso garantiria que tópicos importantes estivessem presentes em todos os projetos.

Por vezes, nos itens de introdução/justificativa, objetivos e metodologia, que formam o corpo do texto, foram detectados alguns erros de concepção sobre o que realmente deve ser tratado em cada um destes itens. Havia ocasiões onde esses tópicos ficaram confusos, como por exemplo: chamar referencial teórico de metodologia ou trocar objetivos gerais com objetivos específicos. A análise mostra que a maioria dos projetos apresentou estes três itens: introdução/justificativa (77\% dos projetos), objetivos $(85,2 \%)$ e metodologia (82\%). Contudo, cronograma e referências bibliográficas apareceram em menos de $40 \%$ dos projetos. Outros itens, como resultados esperados $(<20 \%)$, recursos financeiros $(<10 \%)$ e avaliação pós-projeto $(<5 \%)$ ficaram de forma ainda menos evidente.

A respeito do registro fotográfico do evento, a orientação da "Cartilha passo a passo" diz que duas fotografias deveriam ser postadas no site, demonstrando os debates e a eleição do delegado (BRASIL, 2012a). Estes debates referem-se a fase de elaboração do projeto e o delegado é o 
representante da escola nas etapas seguintes da Conferência. A maior parte dos projetos $(63,1 \%)$ possuía a quantidade de fotos sugeridas na instrução, sendo que destes, $67,3 \%$ apresentaram alguma foto que evidenciava o momento do debate e apenas $8,3 \%$ dos projetos apresentaram alguma foto caracterizando o momento da eleição.

Existem inúmeras maneiras de se divulgar as atividades desenvolvidas pelas escolas, sendo que a Educomunicação foi identificada em $36,9 \%$ dos projetos e, entre algumas das formas mencionadas, estão: apresentação na Feira do Conhecimento/Científica, jornal ou rádio da escola, passeata, distribuição de folhetos, palestra, redes sociais da escola, banner e vídeo. Em geral, as escolas enfatizaram que a intenção era a divulgação junto a sua comunidade (que pode ser a própria comunidade escolar ou a do entorno à escola). Apenas $4,9 \%$ das escolas mencionaram a divulgação dos projetos para outras escolas, seguindo a orientação da Cartilha passo a passo, que menciona que a ideia é formar uma rede para troca de experiências, que venha a fortalecer as ações em cada unidade escolar; o conhecimento produzido não deve ficar apenas dentro da escola (BRASIL, 2012a).

Em $82 \%$ das escolas estava previsto nos projetos a realização de procedimentos que trouxessem algum benefício ao ambiente, as ecotécnicas, sendo que alguns projetos mencionaram mais de uma ação. Notou-se grande relação entre os temas horta, compostagem e cisterna, sendo comum aparecerem associados. Assim, as ações de ecotécnica mais frequentes foram: i) plantio de árvores (26\%); ii) horta (20\%); iii) lixo (16\%); iv) compostagem (11\%); v) cisternas (6\%). Entre as atividades propostas pelas escolas para as ecotécnicas, percebeu-se pouca clareza em como proceder no encaminhamento das mesmas.

Avaliar a clareza dos projetos pode ser subjetivo, mas necessário. Embora a maior parte dos projetos tenha se apresentado de forma clara $(77 \%)$, $23 \%$ deles deixaram dúvidas, não demonstrando sua proposição, ações e objetivos. Outras vezes foi possível compreender a ideia, mas sem nenhuma menção sobre a execução ou de como colocá-la em prática.

Ressalta-se ainda que a Cartilha passo a passo não forneceu orientações de como a escola deveria proceder para envolver a todos: professores, alunos, funcionários, pais e comunidade. Entende-se aqui que cada escola teria a liberdade de encaminhar suas atividades de forma a obter os melhores resultados dentro de sua realidade. A mobilização de toda comunidade escolar, fundamental para que o processo democrático estivesse presente, atendendo aos objetivos da EA e da CNIJMA, foi observada apenas $20,5 \%$ dos projetos, onde ficaram claras as etapas realizadas no processo de mobilização, transparecendo o envolvimento da comunidade de forma democrática. Ressalta-se, contudo, que não foram poucos os projetos onde se percebeu que a definição do tema e elaboração do plano de ação não contou com a participação dos alunos, mas apenas dos professores. Outras vezes, percebeu-se que houve uma preocupação em envolver os alunos a fim de se 
discutir e decidir o que seria trabalhado, mas nestes casos em geral, envolvia apenas uma turma ou série/ano.

Com relação ao envolvimento de várias disciplinas nos projetos, foi comum encontrar no texto dos projetos que o mesmo seria trabalhado de forma interdisciplinar, mas muito comum também a não especificação de como esse trabalho interdisciplinar iria ocorrer. Neste sentido, apenas $20,5 \%$ dos projetos apresentaram alguma descrição das atividades especificando como cada área ou disciplina iria contribuir com o projeto. Muitos projetos poderiam se enquadrar também em outros temas além do escolhido, conforme o enfoque estabelecido para cada problema abordado ou ação proposta na escola, a exemplo dos resíduos sólidos (lixo), que poderia ser trabalhado sob a perspectiva do tema água, com foco na contaminação do lençol freático, ou terra, ao se abordar a contaminação do solo. O tema fogo poderia ser abordado na produção de energia a partir do gás metano e o ar ao se evitar sua contaminação pela queima do lixo, tanto nos lixões como nos quintais de residências.

\section{Discussão}

O desempenho de Mato Grosso no programa Vamos Cuidar do Brasil nas Escolas, IV CNIJMA, foi relativamente baixo comparando com os demais Estados, o que pode ser atribuído à grande extensão territorial (terceira maior do país), à greve dos professores da rede estadual ocorrida no decorrer do Projeto e, provavelmente, às estratégias de ação de divulgação e estímulo utilizadas, que não devem ter sido eficientes, necessitando averiguar-se a atuação dos Centros de Formação e Atualização dos Profissionais de Educação Básica (Cefapros), que possui quinze unidades estrategicamente distribuídas em Mato Grosso. Alguns Estados se destacam neste aspecto, a exemplo do Ceará, que apresentou bons resultados na IV CNIJMA. De acordo com Brasil (2006, p. 19), "nota-se que nos Estados onde há uma rede consolidada de gestores das regionais de educação, como o Ceará, o processo é bem-sucedido". Porém, vale mencionar que, conforme Spazziani e Macedo (2013, p. 440) "muitos projetos são compreendidos como mais uma tarefa a ser cumprida, e em vista das condições atuais das escolas públicas brasileiras, pode-se compreender a baixa receptividade de programas vindos de órgãos centrais e as dificuldades de articulação com as ações já realizadas na escola".

Nas diferentes regiões de planejamento de Mato Grosso, constatou-se que o maior percentual de escolas participantes neste Programa não ocorreu na capital do Estado, que tem maior concentração de população e escolas, mas sim no interior, na Região $X$, que tem Sorriso como cidade polo. Esta região do Estado tem sua economia baseada no agronegócio, que se caracteriza por grandes e médias fazendas tecnológicas de produção de grãos e inúmeros conflitos sociais, econômicos e ambientais, como documentado por Schwenk e Cruz (2008, p. 510). Segundo estas autoras, a solução para estes conflitos está na "compreensão e resolução de múltiplas questões que se 
entrelaçam nos planos político, econômico, cultural e ecológico", todos tendo transversalidade com o plano educacional e vice-versa. Neste sentido, pode-se inferir que a CNIJMA atendeu em parte às demandas educacionais necessárias às escolas desta região mato-grossense que se inscreveram neste Programa, provavelmente por se tratar da região mais rica e com municípios com os mais elevados IDHs (Índice de Desenvolvimento Humano) do Estado, o que inclui uma boa estrutura nas escolas públicas.

Por outro lado, na região de planejamento da capital do Estado, onde se concentra a maior parte de sua população e onde estes conflitos também se fazem presentes com outros fatores envolvidos, principalmente relacionados ao uso da água para a diluição de esgotos domésticos e industriais e ocupação de áreas de preservação permanente (RONDON-LIMA; LIMA, 2009, p. 145), o alcance da CNIJMA foi abaixo do esperado, pois em termos quantitativos não atendeu às demandas educacionais desta região.

Entre os materiais elaborados pelo Programa para serem utilizados pelas escolas na organização de suas Conferências, além da cartilha Vamos Cuidar do Brasil com Escolas Sustentáveis - passo a passo para a conferência de Meio Ambiente na escola, foram disponibilizadas outras referências como Formando Com-Vida e Construindo Agenda 21 na Escola, bem como informações diversas no site da conferência/MEC. Deve-se ressaltar que o material impresso só chegou às escolas após a culminância do evento. Neste sentido, constatou-se através dos projetos, que nenhuma escola utilizou e analisou detalhadamente todos os materiais disponíveis no site, que além de orientar sobre a elaboração dos projetos, apresenta aspectos conceituais e epistemológicos da EA, o que pode, em parte, explicar as falhas constatadas na maioria dos projetos.

Quanto ao aspecto conceitual, um dos objetivos da PNEA (Brasil, 1999, p. 02) é "o desenvolvimento de uma compreensão integrada do meio ambiente em suas múltiplas e complexas relações, envolvendo aspectos ecológicos, psicológicos, legais, políticos, sociais, econômicos, científicos, culturais e éticos", que é complementado com outro objetivo desta Política, que é estimular e fortalecer "uma consciência crítica sobre a problemática ambiental e social". Neste sentido, observou-se que, na grande maioria dos projetos analisados, a EA foi tratada de forma ingênua e superficial e desligada do contexto social, ambiental e cultural no qual se insere a escola.

Outro objetivo da EA preconizado na PNEA, referente ao fomento e o fortalecimento da integração com a ciência e a tecnologia, pode ser constada nos projetos através das ecotécnicas, apresentadas pela grande maioria das escolas. A maioria dos projetos, voltados para plantio de árvores, horta e compostagem do lixo, apresentaram pouca clareza dos objetivos e de seu caráter multidisciplinar, uma vez que poderiam conectar os temas com água, alimentação saudável, destino adequado do lixo orgânico, proteção do solo, entre outros. A horta nas escolas proporciona a assimilação de conhecimentos relativos à preservação do meio ambiente, cultivo sustentável de hortaliças, 
problemas ambientais e aplicação da teoria relacionada a boas práticas ambientais e alimentação saudável (RAMOS et al., 2018).

O diagnóstico da escola, denominado Marco Zero, é fundamental para se conhecer a sua realidade socioambiental e embasar os projetos. Porém, esta atividade não foi apresentada nos projetos pela maioria das escolas. É provável que os coordenadores dos projetos pudessem empiricamente conhecer esta realidade, que pode até ter embasado as atividades propostas, mas esta não foi explicitada nos projetos e, tudo indica que não tenha sido difundida na escola, divergindo de um dos objetivos do PNEA, que é garantir a democratização de informações ambientais, e dos próprios objetivos da CNIJMA.

Com relação à interdisciplinaridade, um dos princípios basilares da EA, também constatou-se falhas na percepção da sua importância, do seu conceito e da prática do trabalho interdisciplinar. A própria orientação da cartilha para escolha de um dos quatro temas não se mostrou adequada à interdisciplinaridade, pois se mostrou limitadora e fragmentou as questões ambientais, além de impor uma escolha do que seria trabalhado nas escolas, contraditório aos princípios do próprio programa.

Como exemplo, cita-se o tema água, que é amplo, com diferentes enfoques e que requer uma abordagem integrada, onde os conceitos, procedimentos e atitudes estejam relacionados nas diferentes disciplinas (BACCI; PATACA, 2008). Para as autoras, uma educação para a água não deve se apoiar apenas na compreensão sobre a hidrosfera ou nos usos que fazemos dela, mas na integração dessa esfera com as demais (biosfera, litosfera e atmosfera) e nas interferências humanas em seu meio. Com isso, é possível evitar a fragmentação do conhecimento, que predomina no ambiente escolar, permitindo uma reflexão que leve a novas possibilidades de mudanças do contexto atual. Dessa forma, para que o estudo sobre o tema água se torne significativo, no sentido de integrar diferentes conhecimentos, é imprescindível analisá-lo no contexto da bacia hidrográfica (BACCI; PATACA, 2008, PALMEIRO; GIOPPO, 2011, BERGMANN; PEDROSO, 2008, TUNDISI; SCHIEL, 2003). Esta abordagem por bacia não foi mencionada claramente em nenhum projeto que adotou o tema água, mesmo tendo sido mencionada na Cartilha (subtema água), embora de forma rápida e pouco profunda. De acordo com Moreira et al. (2013, p. 82-83), nas Com-Vida, "a autoridade e o poder são compartilhados, sem hierarquias, possibilitando a aprendizagem e o exercício da cidadania, pois estimula crianças, jovens e adultos (...) participarem ativamente das tomadas de decisão, mas também a assumirem responsabilidades". Os autores citam ainda que as CNIJMA "constituem um pretexto pedagógico para inserir a dimensão política do meio ambiente nos debates sobre a sustentabilidade socioambiental e a Gestão da Água constitui um dos temas mais presentes" (MOREIRA et al., 2013, p. 82), ou deveriam constituir, uma vez que na maioria dos projetos avaliados no presente estudo essa gestão foi tratada apenas dentro da escola, desvinculado dos mananciais de origem desta água. 
Spazziani (2012) menciona que as conferências escolares facilitam a promoção do processo de descentralização da Educação Ambiental, no entanto os materiais didáticos utilizados apresentam propostas que direcionam os temas e conteúdos a serem trabalhados nas escolas, dificultando a implantação do programa conforme os objetivos anunciados. Castro e Baeta (2002) ressaltam que a EA é uma área do conhecimento que se compõe pela interligação de diversos fatores, sendo, portanto, eminentemente interdisciplinar.

Um estudo realizado por Spazziani e Macedo (2013) constatou que $71 \%$ dos profissionais que representaram suas escolas em um Seminário de formação para a participação na II CNIJMA eram da área de biologia ou geografia, o que confirma o entendimento de que a Educação Ambiental ainda está vinculada aos conhecimentos de Ciências Biológicas e da Terra, dificultando práticas interdisciplinares. A promoção da Educação Ambiental e a sua realização adequada pressupõem o esforço da interdisciplinaridade efetiva, na qual, os professores possam trabalhar a realidade vivenciada com sua disciplina estabelecendo também ligação entre as outras disciplinas (ZUQUIM; FONSECA; CORGOZINHO, 2010).

González-Gaudiano (2005) ao fazer a distinção entre a multidisciplina e interdisciplina, diz que na primeira ocorre uma justaposição das disciplinas e na outra a integração de métodos e conceitos de várias disciplinas. Essa diferença conceitual ficou evidente nos projetos analisados, onde no lugar de uma integração entre as disciplinas, o que se observou foi apontamento de conteúdos que seriam trabalhados em cada disciplina. Neste aspecto, pode-se inferir que os projetos que tiveram em suas propostas a realização de um trabalho interdisciplinar, conseguiram nos melhores resultados um trabalho multidisciplinar, uma vez que ocorreram de forma isolada, sem um planejamento conjunto, dialógico e articulado. Dessa forma, a interdisciplinaridade deve ser uma política de educação, que se inicia com a formação dos professores nos cursos de licenciatura, estes também constituídos de forma interdisciplinar.

\section{Conclusões}

Nesta pesquisa foi identificado que os projetos não abordaram o aspecto social, de caráter questionador sobre o atual modelo de sociedade no qual estamos inseridos. Atualmente, o desafio de fortalecer uma Educação Ambiental convergente e multirreferencial é prioritário para viabilizar uma prática educativa que articule de forma incisiva a necessidade de se enfrentar concomitantemente a degradação ambiental e os problemas sociais (JACOBI, 2003).

Os projetos apresentaram uma abordagem conservadora, propondo atividades que procuram mitigar os efeitos do modelo capitalista, mas não questioná-lo ou propor mudanças que contrariem este modelo dentro do 
ambiente escolar. A presença de uma concepção conservadora do meio ambiente nas escolas também foi verificada por Machado e Teixeira (2011) que realizaram uma pesquisa junto a alunos do Ensino Médio de uma escola urbana, com o objetivo de identificar as representações sociais de meio ambiente desses sujeitos. "A visão socioambiental orienta-se por uma racionalidade complexa e interdisciplinar e pensa o meio ambiente não como sinônimo de natureza intocada, mas como um campo de interações entre a cultura, a sociedade e a base física e biológica" (CARVALHO, 2012, p. 37). Desta forma, a visão socioambiental reconhece que a natureza é composta também das relações sociais e culturais, ou seja, que somos parte da natureza, abordagem pouco comum nas escolas, como indicado nos projetos analisados neste estudo. Sousa et al. (2017, p. 185) observaram que, em média, apenas $11 \%$ do total de alunos que entrevistaram se consideram parte integrante da natureza, sendo que $36 \%$ consideram que a "natureza que deve ser preservada e intocada" e $47 \%$ como sendo o local de onde são retirados os recursos naturais para o uso humano.

Mais de dez anos se passaram desde a I CNIJMA e, "embora essa ação tenha sido tratada como um "Programa", no sentido de caracterizar-se como uma ação de política pública, não chegou a ser institucionalizada como tal por um instrumento legal". Esta informação foi obtida em 26 de agosto de 2015 através de consulta ao e-SIC/MEC, protocolada em 06 de agosto de 2015 (ACESSO À INFORMAÇÃO, 2015). Porém, o MEC já disponibilizou em seu portal as informações necessárias para as inscrições da quinta edição da CNIJMA, cujo tema será Cuidando das águas e cuja etapa escolar deve ocorrer até março de 2018 (BRASIL, 2017), evidenciando, ao menos, a continuidade das Conferências.

Para Spazziani (2012, p. 34) a formação continuada de professores e alunos, um dos objetivos da EA, conforme a PNEA, e o "surgimento de novas lideranças ambientalistas nas escolas só se fazem quando cada escola e sua comunidade mergulharem e refletirem suas questões, limites e possibilidades como temas ambientais".

Os resultados deste trabalho apontam para a falta de conhecimento da realidade ambiental em que a escola está inserida e, desconhecer essa realidade, dificulta e cria obstáculos atuais e futuros para a formação de cidadãos que participem ativamente e de forma democrática da gestão ambiental. Conhecer a realidade ambiental permite que se possa intervir, modificar e melhorar esta realidade de forma democrática e participativa. " $A$ sensibilização ambiental da população é um fator importante no questionamento social das realidades ambientais, podendo levar a reivindicações e mudanças das políticas públicas para o setor" (MAGALHÃES JR., 2014, p. 74). 


\section{Referências}

ACESSO À INFORMAÇÃO. Governo Federal. Disponível em: $<$ http://www.acessoainformacao.gov.br> Acesso em: jul.-out. 2015.

BACCI, D.C.; PATACA, E.M. Educação para a água. Estudos Avançados, São Paulo, v. 22, n. 63, p. 211-226, 2008.

BERGMANN, M.; PEDROZO, C.S. Explorando a bacia hidrográfica na escola: contribuições à Educação Ambiental. Ciência \& Educação (Bauru), Bauru, v. 14, n. 3, p. 537-553, 2008.

BRASIL. Ministério da Educação. Lei n. 9.795 de 27 de abril de 1999. Dispõe sobre a Educação Ambiental, institui a Política Nacional de Educação Ambiental e dá outras providências. Diário Oficial da União, Brasília, 28 de abr. 1999.

BRASIL. Ministério da Educação: Ministério do Meio Ambiente. Relatório Final da Conferência Nacional Infantojuvenil pelo Meio Ambiente. Brasília, 2003. 40p. Disponível em: <http://conferenciainfanto.mec.gov.br/2012-05-22-18-2937/2012-05-30-19-46-17>. Acesso em: 29 ago. 2015.

BRASIL. Ministério da Educação : Ministério do Meio Ambiente. II Conferência Nacional Infanto-Juvenil pelo Meio Ambiente - Relatório Final. Luziânia/Brasília, 2006. 65p. Disponível em: <http://conferenciainfanto.mec.gov. br/2012-05-22-18-29-37/2012-05-30-19-46-17>. Acesso em: 29 ago. 2015.

BRASIL. Ministério da Educação: Ministério do Meio Ambiente. III Conferência Nacional Infanto-Juvenil pelo Meio Ambiente / mudanças ambientais globais - Relatório Final. Luziânia - GO / Brasília - DF, 2009. 122p. Disponível em: <http://conferenciainfanto.mec.gov.br/2012-05-22-18-2937/2012-05-30-19-46-17>. Acesso em: 29 ago. 2015.

BRASIL. Ministério da Educação, Secadi: Ministério do Meio Ambiente, Saic. Passo a passo para a Conferência de Meio Ambiente na Escola + Educomunicação: escolas sustentáveis. Brasília, DF: MEC. 2012a. 56p.

BRASIL. Ministério da Educação, Secadi: Ministério do Meio Ambiente. Vamos cuidar do Brasil com escolas sustentáveis: educando-nos para pensar e agir em tempos de mudanças socioambientais globais. Brasília, DF MEC. 2012b. 49p.

BRASIL. Ministério da Educação. Secretaria de Educação Básica. Secretaria de Educação Continuada, Alfabetização, Diversidade e Inclusão. Conselho Nacional de Educação. Diretrizes Curriculares Nacionais Gerais da Educação Básica. Jaqueline Moll (Org.). Brasília : 2013. 562p. Disponível em: $<$ http://portal.mec.gov.br/index.php?option=comdocman\&view=download\&alias $=15548$-d-c-n-educacao-basica-nova-pdf\&ltemid=30192>. Acesso em: 03 jun. 2016. 
BRASIL. Ministério da Educação. V Conferência Nacional Infantojuvenil pelo Meio Ambiente. Disponível em: <http://conferenciainfanto.mec.gov.br/20132014-iv-cnijma>. Acesso em: $01 \mathrm{dez} .2017$.

CARVALHO, I.C.M.. Educação Ambiental e a formação do sujeito ecológico. 6 ed. - São Paulo : Cortez, 2012. 255p.

CASTRO, R.S.; BAETA, A.M. Autonomia intelectual: condição necessária para o exercício da cidadania. In: CASTRO, R.S.; LAYRARGUES, P.P.; LOUREIRO, C.F.B. Educação Ambiental: repensando o espaço da cidadania. São Paulo: Cortez, p. 99-107, 2002.

COORDENAÇÃO GERAL DE EDUCAÇÃO AMBIENTAL. IV CNIJMA conclui $1^{\text {a }}$ Etapa com 16.945 escolas. Ministério da Educação, 20 SET. 2013. Disponível em: <http://conferenciainfanto.mec.gov.br/noticias/9-outrosdestaques/93-iv-cnijma-conclui-1-etapa-com-16-945-escolas>. Acesso em: 17 set 2015.

CRUZ, L.G.; MAIA, J.S.S. Educação Ambiental na prática dos professores da educação básica: políticas públicas e desenvolvimento sustentável. Ambiente \& Educação, v. 20, n.1, p. 4-16, 2015.

DOURADO, J.; BELIZÁRIO, F.; PAULINO, A. Escolas Sustentáveis. São Paulo: Oficina de Textos, 2015.

FERREIRA, L.C.; MARTINS, L.C.G.F.; PEREIRA, S.C.M.; RAGGI, D.G.; SILVA, J.G.F. Educação Ambiental e Sustentabilidade na Prática Escolar. Revbea, V. 14, n. 2: 201-214. 2019.

FIGUEIREDO, D. M.; SALOMÃO, F. X. T. (orgs). Bacia do rio Cuiabá: uma abordagem socioambiental. Cuiabá: Entrelinhas-EdUFMT, 2009.

FRIGOTTO, G. O enfoque da dialética materialista histórica na pesquisa educacional. In: FAZENDA, Ivani Catarina Arantes (Org.) Metodologia da pesquisa educacional. 12 ed. São Paulo: Cortez, 2010.

GONZÁLEZ-GAUDIANO, E. Interdisciplinaridade e Educação Ambiental: explorando novos territórios epistêmicos. In: SATO, Michele; CARVALHO, Isabel Cristina de Moura (Orgs.). Educação Ambiental: pesquisa e desafios. Porto Alegre : Artmed, 2005.

JACOBI, P. Educação Ambiental, cidadania e sustentabilidade. Cadernos de Pesquisa, n. 118, mp. a1rç8o9/-220050,3 março/ 2003

LAYRARGUES, P.P.; LIMA, G.F.C. As macrotendências político-pedagógicas da Educação Ambiental brasileira. Ambiente \& Sociedade, São Paulo, v. 17, n. 1, p. 23-40, Mar. 2014.

LIMA, J.P.C.; ANTUNES, M.T.P.; MENDONÇA NETO, O.P.; PELEIAS, I.R. Estudos de caso e sua aplicação: proposta de um esquema teórico para pesquisas no campo da contabilidade. Revista de Contabilidade e Organizações, vol. 6 n. 14 (2012) p. 127-144. 
MACHADO, E.H.S.; TEIXEIRA, E.S. Representações de Meio Ambiente em estudantes do Ensino Médio em uma escola urbana. Synergismusscyentifica - Universidade Tecnológica Federal do Paraná, Pato Branco, v.6, n.1, 2011.

MAGALHÃES JÚNIOR, A.P. Indicadores Ambientais e Recursos Hídricos. Realidade e perspectivas para o Brasil a partir da experiência francesa. $6^{\underline{a}}$ ed. Rio de Janeiro: Bertrand Brasil, 2014. 688 p.

MARCONI, M.A.; LAKATOS, E.M. Técnicas de Pesquisa: planejamento e execução de pesquisas, amostragens e técnicas de pesquisa, elaboração, análise e interpretação de dados. 7 ed. São Paulo : Atlas, 2012. 282p.

MARINHO, A.R.B. Círculo de cultura - origem histórica e perspectivas epistemológicas. 2009. 125f. Dissertação (Mestrado em Educação) Faculdade de Educação, Universidade de São Paulo, São Paulo, 2009.

MATO GROSSO. Secretaria de Estado de Educação. IV Conferência Nacional Infantojuvenil pelo Meio Ambiente: Vamos Cuidar do Brasil com Escolas Sustentáveis. Cuiabá: SEDUC, 2014b. 31p. Relatório.

MINISTÉRIO DA EDUCAÇÃO. IV CNIJMA. CONFERÊNCIA NACIONAL INFANTOJUVENIL PELO MEIO AMBIENTE, 2013. Brasília. Projetos cadastrados na IV CNIJMA por UF. Brasília: Ministério da Educação. Disponivel em: <http://conferenciainfanto.mec.gov.br> Acesso em: abr. 2014.

MOREIRA, T.; BARBOSA, N.H.R.; SANTOS, R.S.; COSTA, L.C.L. Educação Ambiental e gestão das águas no ensino formal. In: Política de águas e Educação Ambiental: processos dialógicos e formativos em planejamento e gestão de recursos hídricos. Brasília: MMA/SRHU, p. 80-85, 2013. PALMEIRO, V.; GIOPPO, C. Ui, que nojo! Tem mais é que fechar esse valetão! Um estudo com o conceito deleuzeano de devir. Educar em Revista, Curitiba, n. 40, p. 85-106, Jun. 2011.

PORTAL BRASIL. Carta sugere 108 projetos para escolas mais sustentáveis. Ministério do Meio Ambiente, 27 nov. 2013. Disponível em: $<$ http://www.brasil.gov.br/meio-ambiente/2013/11/carta-sugere-108-projetospara-escolas-mais-sustentaveis> Acesso em: 18 nov. 2015.

QEDU. Disponível em: <http://www.qedu.org.br> Acesso em: nov. 2015.

RAMOS, C.A.; MORAES, L.A.; SANTOS, L.A.; VERAS, M.F. Horta escolar: alternativa de Educação Ambiental, Alcântara (MA). Revbea, V. 13, n. 14: 228247

RONDON-LIMA, E.B.N.; LIMA, J.B. Qualidade da água das principais subbacias urbanas do município de Cuiabá. In: FIGUEIREDO, D.M.; SALOMÃO, F.X.T. Bacia do Rio Cuiabá-uma abordagem socioambiental. Cuiabá: Entrelinhas/EdUFMT, 2009. 140-145 p. 
SCHWENK, L.M.; CRUZ, C.B.M. Conflitos socioeconômicos-ambientais relativos ao avanço do cultivo da soja em áreas de influência dos eixos de integração e desenvolvimento no Estado de Mato Grosso. Acta Sci. Agron. Maringá, v. 30, n. 4, p. 501-511, 2008.

SOUSA, C.A.F.; ALVES, A.F.; ANDRADE, T.M.; NICODEMO, S.C.T.S.; VITORINA, G.O. A percepção ambiental de atores sociais de escolas públicas e privadas, em um bairro de João Pessoa (PB). Revista Brasileira de Educação Ambiental, São Paulo, V. 12, No 4: 180-193, 2017.

SPAZZIANI, M.L. A Educação Ambiental no espaço da política pública brasileira. Anais do Encontro Nacional de Didática e Práticas de Ensino, 16, 2012, Campinas (UNICAMP) : Junqueira\&Marin Editores, 2012. Livro 1, p. 3283-3294. Disponível em: <http://www.infoteca.inf.br/endipe/ smarty/templates/arquivos template/upload arquivos /acervo/docs/3251d.pdf> Acesso em: 29 jan.2016.

SPAZZIANI, M.L.; MACEDO, B.S. Política Pública e Educação Ambiental: Possibilidades e dificuldades da Agenda 21 escolar. In: SORRENTINO, Marcos et al. (Org.). Educação Ambiental e Políticas Públicas: Conceitos, Fundamentos e Vivências. Curitiba: Editora Appris, p. 433-450, 2013. 499p.

TOZONI-REIS, M. F.C. Temas ambientais como "temas geradores": contribuições para uma metodologia educativa ambiental crítica, transformadora e emancipatória. Educar em Revista, Curitiba, n. 27, p. 93110, 2006.

TUNDISI, J.G.; SCHIEL, D. A bacia hidrográfica como laboratório experimental para o ensino de ciências, geografia e Educação Ambiental. In: SCHIEL, Dietrich. et al. (Orgs.). $O$ estudo de bacias hidrográficas: uma estratégia para Educação Ambiental. 2 ed. - São Carlos : RiMa, p. 03-08, 2003.

VIVENDO COM CIÊNCIA. Disponível em: <http://vivendocomciencia. blogspot.com.br/> Acesso em: 28 jul. 2015.

ZUQUIM, F.A.; FONSECA, A.R.; CORGOZINHO, B.M.S. Educação Ambiental no Ensino Médio: Conhecimento, Vivências e Obstáculos, 2010. Disponível em: < http://revistaea.org/artigo.php?idartigo $=736 \&$ class=02. $>$. Acesso em: 15 nov. 2016. 